\title{
Healthcare providers' knowledge, attitude and behaviour towards breast cancer diagnosis and treatment in Malaysia - a mini systematic review
}

\author{
Eman Azeem ${ }^{1}$, Syed Wasif Gillani ${ }^{2 *}$, Vinci Poh ${ }^{3}$ and Syed Azhar Syed Sulaiman ${ }^{4}$ \\ ${ }^{1}$ Department of Clinical Pharmacy, Taibah University, Al-Madinah Al-Munawarrah, PO Box 30001, ${ }^{2}$ King Abdul Aziz Military \\ Hospital PSAFH, Tabuk, Kingdom of Saudi Arabia, ${ }^{3}$ School of Pharmacy, Monash University, Malaysia, ${ }^{4}$ School of \\ Pharmaceutical Sciences, Univerisiti Sains Malaysia (USM), Malaysia
}

${ }^{\star}$ For correspondence: Email: wasifgillani@gmail.com; Tel: +966538419573

\begin{abstract}
Breast cancer is the most common cancer among women in Malaysia. Therefore, it is important for the public to be educated on breast cancer and to know the steps that need to be taken to detect it early. Healthcare providers are in a unique position to provide public health education due to their good knowledge of health issues and their roles in healthcare. A systematic review of studies conducted from 2008 till 2015 was undertaken to analyze the knowledge, attitudes and behavior of Malaysian healthcare providers regarding breast cancer, in an attempt to obtain an overall picture of how wellequipped the healthcare providers are to provide optimal breast cancer education, and to ascertain their perceptions and actual involvement in such education. The systematic review was conducted via a primary search of various databases and journal websites, and a secondary search of references cited in eligible studies. Criteria for eligibility include studies conducted in Malaysia and published from the year 2008 to 2015, and written in English language. A total of fifteen articles were identified and reviewed but only two studies were eligible for this review. The findings suggest that future and current Malaysian healthcare providers have moderate knowledge of breast cancer, showed a positive disposition towards involvement in breast cancer education, but displayed poor involvement.
\end{abstract}

Keywords: Healthcare provider, Breast cancer, Knowledge, Attitude, Behavior, Systematic review, Malaysia

Tropical Journal of Pharmaceutical Research is indexed by Science Citation Index (SciSearch), Scopus, International Pharmaceutical Abstract, Chemical Abstracts, Embase, Index Copernicus, EBSCO, African Index Medicus, JournalSeek, Journal Citation Reports/Science Edition, Directory of Open Access Journals (DOAJ), African Journal Online, Bioline International, Open-J-Gate and Pharmacy Abstracts

\section{INTRODUCTION}

Breast cancer is the most common cancer among women in Malaysia, with statistics indicating that 1 out of 19 women are at risk [1]. However, the number of Malaysian women at risk of breast cancer could be much higher than reported as many patients still seek traditional therapy and may not report incidences of breast cancer [2,3]. Also, the national statistics have long been unrevised. [2,4]. Additionally, a review by Yip et al stated that Malaysian women present with breast cancer at an earlier age compared to Western women, due to Malaysia having a comparatively younger demographic, as well as the older population lead a lower-risk lifestyle. This may also be interpreted as the younger generation are leading more high-risk lifestyles, leading to an increasing risk of breast cancer. Furthermore, women in Malaysia present at later stages of breast cancer, meaning a poorer chance of outcome and survival [3]. With all this 
information at hand, it is clear that it is extremely important for Malaysian women to do regular breast examinations for early detection, particularly those at higher risk. Unfortunately, breast cancer awareness and uptake of regular screening is poor among Malaysians [3].

Health care providers are in the prime position to disseminate breast cancer and breast screening awareness and knowledge to the general public. However to be able to do so the health care providers themselves need to be well equipped with sufficient knowledge as well as appropriate attitude and behavior. Therefore it would be useful to obtain a picture of the knowledge, attitude and behavior of healthcare providers within the Malaysian healthcare system in order to understand how much this is affecting the awareness and uptake of screening among Malaysian women, as well as facilitate in the identification of areas for potential improvement.

This study is a limited systematic review of studies that analyze the knowledge, attitude and behavior of healthcare providers towards breast cancer in Malaysia. So far, there are no systematic reviews done on this area within Malaysia in the past 7 years.

\section{METHODS}

A systematic literature search was carried out to identify studies conducted in Malaysia, with no limitations on study design. Our primary search was conducted via database and journal websites, including Asia Pacific Journal of Public Health, Pubmed, Google Scholar, ResearchGate, Scopus, BMC Public Health, National Center of Biotechnology Information (NCBI) and OVID Medline. A secondary search was conducted by scanning through the reference lists of study articles found via the primary search. Searches were limited to studies carried out in Malaysia, published from 2008 till 2015 and written in the English language. The three main search themes include 'knowledge, attitude and behavior', 'healthcare provider' and 'breast cancer', which were combined by the Boolean operator 'and'. Words with similar definition to the aforementioned search terms were also used. The term 'healthcare provider' included both current healthcare related professions as well as health science students that would potentially graduate to work in the healthcare system.
Primary screening of studies were done by reviewing the titles and abstracts of the articles. Any studies that were not focused on breast cancer only, does not focus on health care providers and are not conducted in Malaysia were excluded. Secondary screening was done by examining the full texts of the studies that passed primary screening.

\section{RESULTS}

After primary and secondary screening of fifteen articles, only two articles are eligible for review. Key findings of the two articles are summarized in the table below.

The first study, 'Knowledge, Perception, Practice and Barriers of Breast Cancer Health Promotion Activities among Community Pharmacists in Two Districts of Selangor State, Malaysia' by Beshir et al, focused on pharmacists working in community pharmacies located in Sepang and Hulu Langat, two districts in the state of Selangor. It aimed to analyze their knowledge on breast cancer, their involvement in breast cancer health promotion services and their views on the provision of such services by community pharmacists. This is a cross-sectional study whereby data was collected via face to face interview facilitated by a questionnaire. The questionnaire was separated into three sections: breast cancer risk factors and screening knowledge, perception on breast cancer health promotion and barriers for promotion involvement. Results show a mean overall knowledge of $56 \%$, with only $11.3 \%$ answering all knowledge questions correctly. As for participation in promotion of breast cancer awareness and screening, the participation rate was nil. Major barriers include time constraints (80 \%), lack of breast cancer educational materials $(77.1 \%)$ and lack of staff training (62.9 $\%)$. Other barriers that were mentioned include gender barriers, lack of personnel, lack of budget and lack of profit. Despite this, most of the participants agree on community pharmacist involvement in breast cancer education and that it should be integrated into their daily practice, as they view it as their responsibility as well as an opportunity to improve their profession [5].

The second study, 'Breast Cancer and Chemotherapy Knowledge among Undergraduates of Health Sciences-Which Traits Predict Good Knowledge' by Lua et al, focused on identifying which groups of people have better knowledge on breast cancer and chemotherapy. 
Table 1: A summary of the findings of studies that were reviewed

\begin{tabular}{|c|c|c|c|c|c|c|}
\hline Title & Year & Region & Subjects & Size & Findings & Study Limitations \\
\hline $\begin{array}{l}\text { Knowledge, } \\
\text { Perception, } \\
\text { Practice and } \\
\text { Barriers of Breast } \\
\text { Cancer Health } \\
\text { Promotion } \\
\text { Activities among } \\
\text { Community } \\
\text { Pharmacists in } \\
\text { Two Districts of } \\
\text { Selangor } \\
\text { State, Malaysia [5] }\end{array}$ & 2012 & $\begin{array}{l}\text { Selangor } \\
\text { (Malaysia) }\end{array}$ & $\begin{array}{l}\text { Community } \\
\text { pharmacists }\end{array}$ & 35 & $\begin{array}{l}\text { * } 11.3 \% \text { correctly answered all questions } \\
\text { on knowledge } \\
\text { * mean overall knowledge of } 56 \% \text { on risk } \\
\text { factors and screening recommendations } \\
{ }^{*} \text { Involvement in breast cancer health } \\
\text { promotion activities is zero } \\
\text { * Top } 3 \text { barriers are time constraints } \\
(80 \%) \text {, lack of breast cancer educational } \\
\text { materials }(77.1 \%) \text { and lack of staff } \\
\text { training }(62.9 \%) \\
\text { * } 94.3 \% \text { agreed on the involvement of } \\
\text { breast cancer health promotion activities }\end{array}$ & $\begin{array}{l}\text { * Study participants were taken only } \\
\text { from Hulu Langat and Sepang districts, } \\
\text { hence data cannot be generalized to all } \\
\text { areas in Malaysia }\end{array}$ \\
\hline $\begin{array}{l}\text { Breast Cancer } \\
\text { and } \\
\text { Chemotherapy } \\
\text { Knowledge } \\
\text { among } \\
\text { Undergraduates } \\
\text { of } \\
\text { Health Sciences: } \\
\text { What Traits } \\
\text { Predict } \\
\text { Good Knowledge? }\end{array}$ & 2012 & $\begin{array}{l}\text { Terengganu } \\
\text { (Malaysia) }\end{array}$ & $\begin{array}{l}\text { Health Science } \\
\text { Undergraduates }\end{array}$ & 239 & $\begin{array}{l}\text { * } 7.9 \% \text { have high knowledge, } 71 \% \text { have } \\
\text { moderate knowledge and } 20.9 \% \text { have } \\
\text { poor knowledge on } \\
\text { breast cancer and chemotherapy } \\
{ }^{*} \text { Female gender, final year students and } \\
\text { those in the nursing course exhibit } \\
\text { significantly higher knowledge } \\
\text { * Precise knowledge considered } \\
\text { insufficient and poorly disseminated } \\
\text { considering their tertiary } \\
\text { education in health science }\end{array}$ & $\begin{array}{l}\text { * Convenience sampling- sample not } \\
\text { representative of all undergraduates of } \\
\text { health sciences } \\
\text { * Sample lacks heterogeneity due to } \\
\text { female predominance } \\
{ }^{*} \text { questionnaire administrated at varied } \\
\text { time points } \\
\text { * Cross sectional study- cannot draw } \\
\text { causal relationship between } \\
\text { sociodemographic factors and } \\
\text { knowledge on breast cancer }\end{array}$ \\
\hline
\end{tabular}


The study population was taken from a public university situated in the state of Terengganu, and students enrolled in medical laboratory technician (MLT), nursing or radiography diploma programmes were asked to fill in questionnaires with questions regarding knowledge on breast cancer and chemotherapy. $7.9 \%$ possesses high knowledge, $71.1 \%$ displayed moderate knowledge and $20.9 \%$ show poor knowledge. Female gender, final year students and those in the nursing course exhibit significantly higher knowledge compared to other groups. These findings could be due to breast cancer affecting females predominantly, as well as the majority of respondents being female; final year students would be at an advantage compared to other years due to experiencing more education of the syllabus; and the role of nurses in clinical care would lead to nursing students being more informed about breast cancer information. Overall, most have a moderate level of knowledge despite being health science undergraduates, limiting their ability to become role models and educators of breast cancer knowledge to the public. This study did not analyze the attitudes and behaviors' of the students towards breast cancer [6].

\section{DISCUSSION}

One study focused on healthcare providers (community pharmacists) and one study focused on potential healthcare providers (health science undergraduates). Both showed an overall moderate level of knowledge towards breast cancer despite undergoing or having undergone tertiary education on health science. However, allowance should be made for the knowledge of the students, as some may not have reached the stage of their syllabus to study on breast cancer [6]. Nevertheless, there is much room for improvement as breast cancer is very common, and early detection is as easy as doing a breast self-examination (BSE) every month, which does not cost anything, and this can help women to detect and hence remove tumors in the breast before they metastasize [7]. It would be extremely beneficial for the population if all healthcare providers could do proper promotion of breast cancer education. Training programmes organized by private or government sectors could help enhance knowledge on breast cancer among healthcare personnel. As for students, further analysis should be made on whether insufficient knowledge on breast cancer was caused by syllabus inadequacy or problems of the learning process [6].
Only the first study done on community pharmacists included findings on attitude and behavior of healthcare providers towards dissemination of breast cancer education. A majority of the pharmacists involved in the study had a positive attitude towards breast cancer health promotion involvement, and considered it to be their responsibility as well as a chance to enhance the status of their profession. Despite that, actual participation was nil, due to the existence of many organizational barriers. Therefore, should these organizational barriers be overcome and facilitators be provided, it would be expected that participation would be high.

Through this systematic review it can be seen that there has not been many studies made to analyze the knowledge, behavior and attitude of healthcare providers towards breast cancer in the past 7 years. There is still no data on other healthcare providers such as physicians, nurses, hospital pharmacists, medical officers and so forth; students from other health science courses have not been studied as well. There ought to be more studies on this area, and similar studies ought to be done every few years as these parameters can change over time, therefore older studies would not truly reflect the current situation and therefore may not provide an accurate picture. Also, this could help map out any patterns or degree of progress which could help in the understanding of whether any actions taken to improve these parameters have been successful, and can aid in the determination of areas that require improvement. An overall picture of different healthcare professions would be helpful in the planning of any programs, policies or healthcare structure reorganizations to facilitate their involvement in breast cancer education.

\section{Limitations of the study}

a. Study is limited to two studies only, and so a countrywide survey is required to address certain perception aspects of breast cancer diagnosis.

b. Regional influence on treatment and diagnosis affects the outcomes of breast cancer attitude and knowledge; thus, Asia-Pacific regional literature review is required to clarify and affirm any proffered interpretation.

c. Exploratory qualitative study is required to identify barriers or limitations among healthcare providers on breast cancer diagnosis and treatment. 


\section{CONCLUSION}

In Malaysia, current and future health care providers possess moderate knowledge on breast cancer awareness and have very positive attitudes to involvement in breast cancer education, but unfortunately have poor actual involvement due to numerous organizational barriers. However, the findings of this systematic review are extremely limited due to the fact that only two studies met the review criteria, with the sample population taken from very specific profession groups. Also, the samples of both studies were taken from only one or two population areas, and the sample sizes were relatively small, hence findings may not be applicable to Malaysian healthcare providers in general. Further systematic reviews on local studies should be done when more studies on this topic are available. It is important to have systematic reviews that focus on local studies as the knowledge, behaviors and attitudes of healthcare providers differ from region to region.

\section{DECLARATIONS}

\section{Acknowledgement}

The authors would like to express their gratitude to Dr. Hani Khowja (TU) and Dr. Ammar Siddiqui $(\mathrm{HU})$ for providing use comments on content interpretation and manuscript writing.

\section{Conflict of Interest}

No conflict of interest associated with this work.

\section{Contribution of Authors}

The authors declare that this work was done by the authors named in this article and all liabilities pertaining to claims relating to the content of this article will be borne by them.

\section{REFERENCES}

1. PRIDE Foundation. Breast Cancer [Internet]. c2014 [cited 2015 Mar 1]. Available from: http://pride.org.my/breastcancer/

2. More women may be dying of breast cancer in M'sia than statistics indicate, says expert. The Star Online [Internet]. 2012 [updated 2013 Jun 2; cited 2015 Mar 1] Oct 13. Available from: http://www.thestar. com.my/News/Nation/2012/10/13/More-women-may-bedying-of-breast-cancer-in-Msia-than-statistics-indicatesays-expert/

3. Yip $\mathrm{CH}$, Bhoo Pathy $\mathrm{N}$, Teo $\mathrm{SH}$. A review of breast cancer research in Malaysia. Med J Malaysia [Internet]. 2014 [cited 2015 Mar 1]; 69 Suppl A: 8-22. Available from: Pubmed

4. National Cancer Registry. Malaysia Cancer Statistics Data and Figure Peninsular Malaysia 2006 [Internet]. National Cancer Registry, Ministry of Health Malaysia; 2006 [cited 2015 Mar 3]. Available from: http://www.moh.gov.my/images/gallery/Report/Cancer/M alaysiaCancerStatistics_2006.pdf

5. Beshir SA, Hanipah MA. Knowledge, Perception, Practice and Barriers of Breast Cancer Health Promotion Activities among Community Pharmacists in Two Districts of Selangor State Malaysia. Asian Pac J Cancer Prev [Internet]. 2012[cited 2015 Mar 3]; 13(9):4427-30. Available from: Pubmed

6. Lua PL, Zakaria NS. Breast Cancer and Chemotherapy Knowledge among Undergraduates of Health SciencesWhich Traits Predict Good Knowledge? Malays J Med Sci [Internet]. 2013 [cited 2015 Mar 4]; 20(1): 60-68. Available from: PubMed Central

7. American Cancer Society. Breast Cancer Prevention and Early Detection [Internet]. c2015 [updated 2014 Oct 9; cited 2015 Mar 5]. Available from: http://www.cancer. org/cancer/breastcancer/moreinformation/breastcancere arlydetection/breast-cancer-early-detection-toc 